\title{
The new cemented paste backfill recipes selection method at Newmont Éléonore mine
}

\author{
C Carlier Newmont Corporation, Canada \\ RL Veenstra Newmont Australia, Australia
}

\begin{abstract}
Until mid-2020, the Newmont Éléonore mine cemented paste backfill (CPB) recipes were chosen from charts comparing binder contents and strengths at specific curing ages up to 56 days. However, these charts were based on Mitchell's method using Éléonore's biggest stope dimensions. They also did not consider any rheology, maximum surface pump pressure capacities or mix density.

Using the new system, and its resulting template, backfill personnel can tailor a recipe for each stope to meet the latest sequence and environment conditions.

This paper explains how the new paste recipes are selected, as well as the costs savings and productivity increases they enabled.
\end{abstract}

Keywords: cemented paste backfill recipes, rheology, selection template, binder, costs

\section{Cemented paste backfill system at Éléonore}

Éléonore mine is an underground (UG) gold mine in the James Bay region of Quebec, Canada, as shown in Figure 1. The ore is mined from five, soon becoming six, horizons of $30 \mathrm{~m}$ high sublevel stopes, as shown in Figure 2. It is then processed onsite using a conventional circuit that includes crushing, grinding, gravity, floatation and cyanidation. UG voids are backfilled using cemented paste backfill (CPB) and waste rockfill.

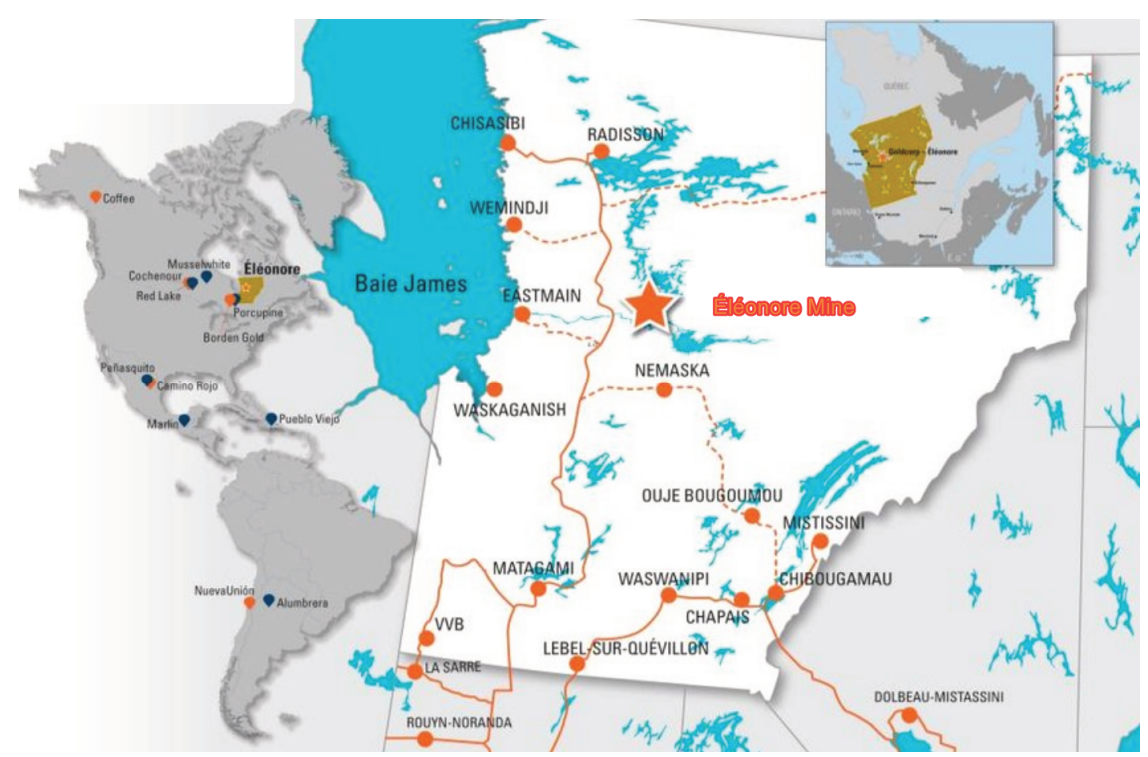

Figure 1 Éléonore mine location (Guido et al. 2017, modified) 


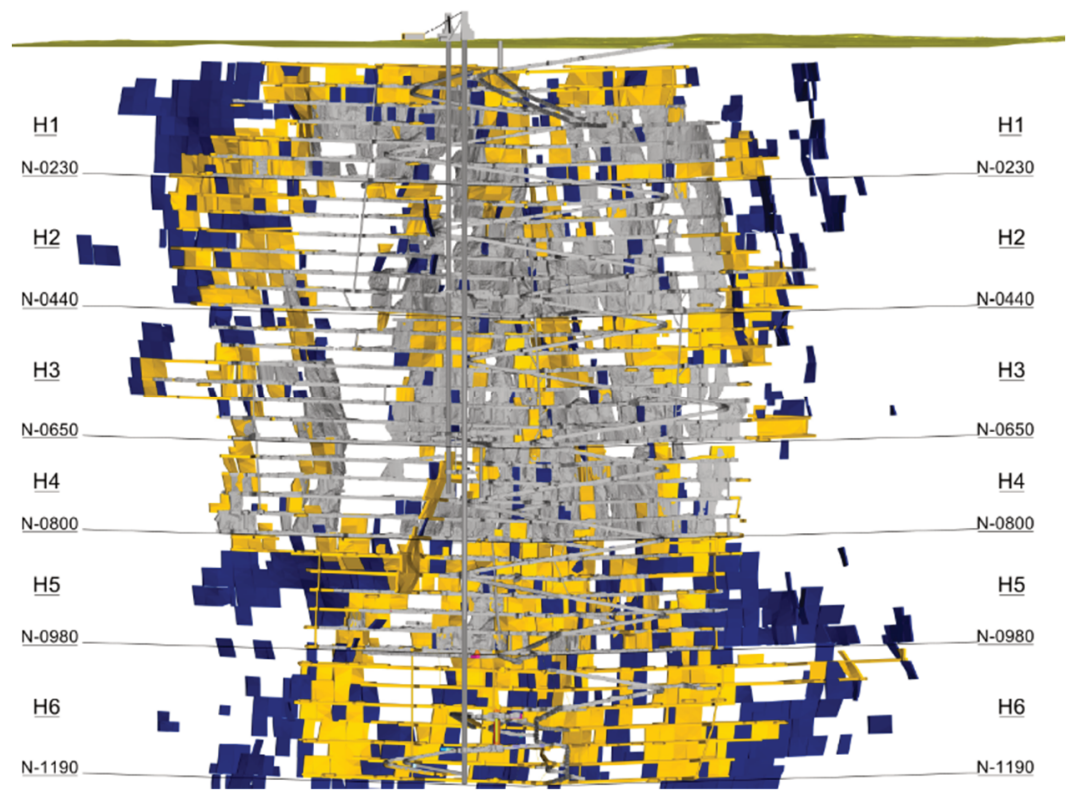

Figure 2 Mining horizons looking west (grey stopes are mined-out stopes, and gold and blue are planned stopes)

The Éléonore CPB system has four challenges: the layout of its reticulation system, the CPB's ingredients and consistency, the water inflow into the UG stopes, and its widespread use of CPB in preference of rockfill.

\subsection{Reticulation system}

The UG CPB reticulation system starts with a flat section ( $10 \%$ decline) of about $1 \mathrm{~km}$, from the portal to the first mining areas under the Opinaca Reservoir. For that reason, the paste system is driven by a positive displacement piston pump.

Figure 3 shows the current reticulation system. There are the two main lines from surface to the 740 level: one at the centre of the orebody (red line in Figure 3 ) and one at the northern end of the orebody (magenta line in Figure 3). Below the 740 level, the central line continues to the 950 level.

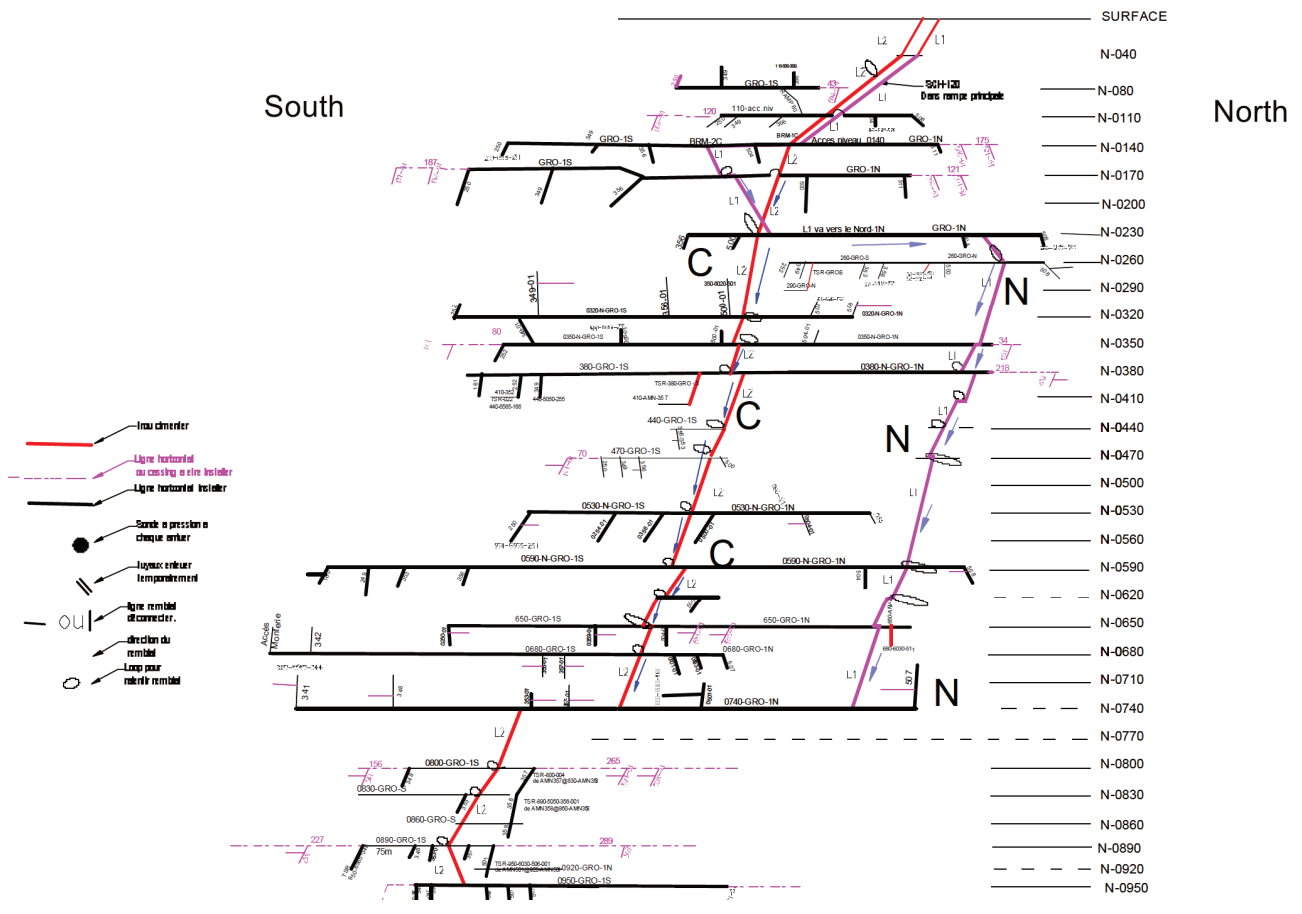

Figure 3 Éléonore backfill paste reticular system 
The main paste boreholes are all cased and grouted with $204 \mathrm{~mm}$ schedule 120 pipes, while the main drives and cross-cuts are $204 \mathrm{~mm}$ schedule 80 . This changes to $204 \mathrm{~mm}$ schedule 40 for the ore drives and can reduce to $102 \mathrm{~mm}$ schedule 20 pipes for specific installations.

\subsection{Paste ingredients and consistency}

Éléonore's CPB is made from four ingredients:

- Non-sulphides cake.

- Plant sulphides tailings.

- Binder.

- Processing water.

For environmental reasons, all of the sulphide tailings needs to be placed UG as backfill, so it is only temporally stockpiled in a buffer tank on-surface until mixed. The sulphide tailings are mixed with non-sulphide cake in proportions varying from 0 to $25 \%$ by dry mass concentration. Sulphide contents of over $25 \%$ make it too difficult to reticulate the CPB. Generally, Éléonore's CPB has a percent solid (Mass solids $_{\text {Mass }}$ total) range of between 69 and $71 \%$.

The binder is a $90 / 10$ blend of blast furnace slag and normal Portland cement. Its proportion in paste varies between 3.0 and 6.5\% ( Mass binder/ $_{\text {Mass }}$ solids).

\subsection{Water inflows}

As mentioned previously, the Éléonore mine is located beneath the Opinaca Reservoir. Open sub-horizontal decompression joints mainly within the first $150 \mathrm{~m}$ below the surface bring water into the mining areas. They are usually grouted before mining begins, but it is still common for water to infiltrate into a stope. This either requires the water to be removed from the stope prior to filling or increasing the CPB binder content to compensate for any decreased CPB density due to the extra water.

\subsection{Widespread use of CPB instead of rockfill}

CPB is regularly used instead of the scheduled rockfill in order to:

- Speed up the production cycle.

- Avoid high seismicity zones by filling the empty stopes faster.

- Contain the water inflows as a last-minute grouting system.

The increase in CPB filled stopes means that the mix designs in these stopes need to account for any blasting related instability risk.

\section{Reasons for the recipe template}

In 2020, both tailings streams were ground finer to increase gold recovery. Following this change in tailings particle size distribution (PSD), Éléonore decided to modify the whole recipe selection process. Additionally, other reasons called for a reformulation of the recipes, including inconsistent decision making, change in stope dimensions and mining sequence, lower strength requirements, and not linking the CPB's mix density to its strength requirement.

\subsection{Change in tailings PSD}

The change in PSD is shown in Figure 4. After 2020, the non-sulphides P80 changed from 63 to $58 \mu \mathrm{m}$ while the sulphides tailings P80 changed from 17 to $13 \mu \mathrm{m}$. This change impacted the quality of the paste because the same strength was not reached at the same curing age with the same recipe. The finer CPB now operated 
at a lower density which required additional binder addition. New rheological testing was done to better understand the impact.

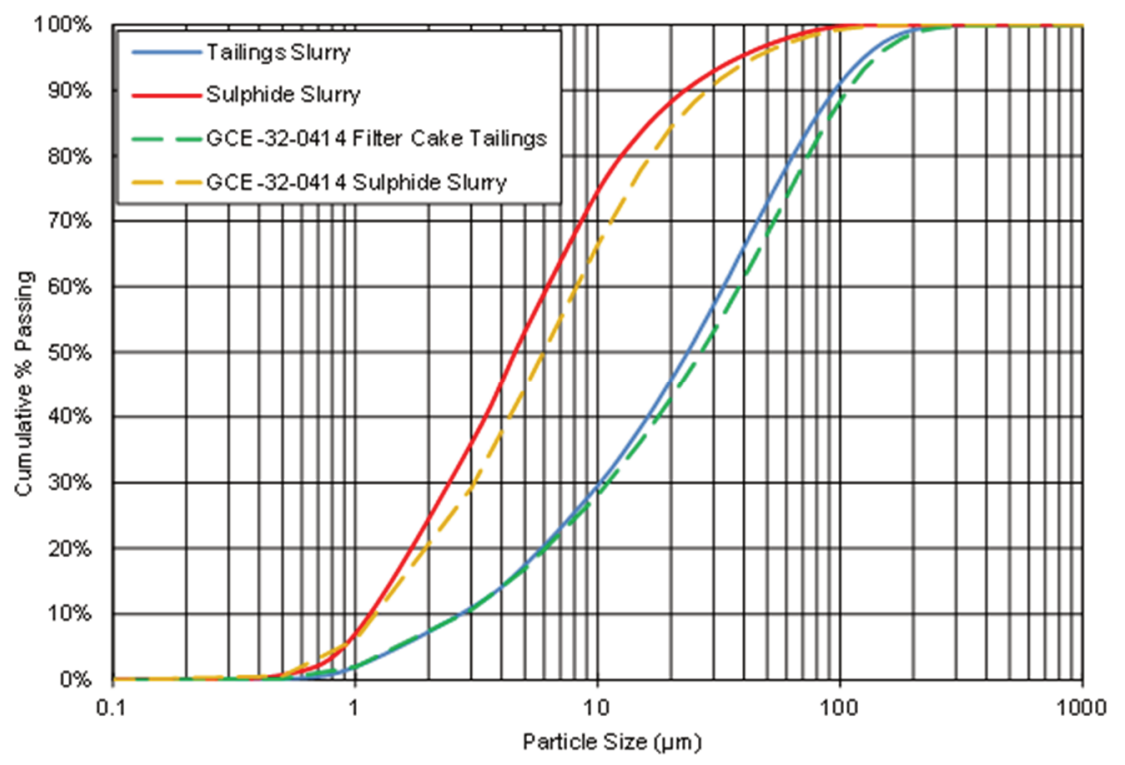

Figure 4 Particle size distribution (dashed lines are from pre-2020 samples) (Paterson \& Cooke Canada Inc., pers. comm., 21 January 2021)

This work was completed in early 2020 (Paterson \& Cooke Canada Inc. 2020), with various recipes over a range of solids mass concentrations and binder content. The rheology testwork consisted of yield stress and viscosity determination. The unconfined compressive strength (UCS) was tested on samples cured for 1, 2, 7, $14,28,56$, and 112 days.

From there, the water:binder ratios were determined for each sulphides content tested. This relationship expresses the binder consumption in terms of a unit of binder required per unit of water present in a unit of backfill, for a specific strength and curing age. Increasing the sulphides content requires more water to be added to the mix, allowing it to be reticulated. This decreases the percent solids, which requires an increase in binder content to keep the same strength. An example for the 0 and $20 \%$ sulphides is shown in Figure 5 . These ratios make possible the conversion between the recipes at different \% sulphides; for the same strength at a specific curing age, if the water:binder ratio increases compared to the initial recipe, the required binder content decreases for the new recipe.

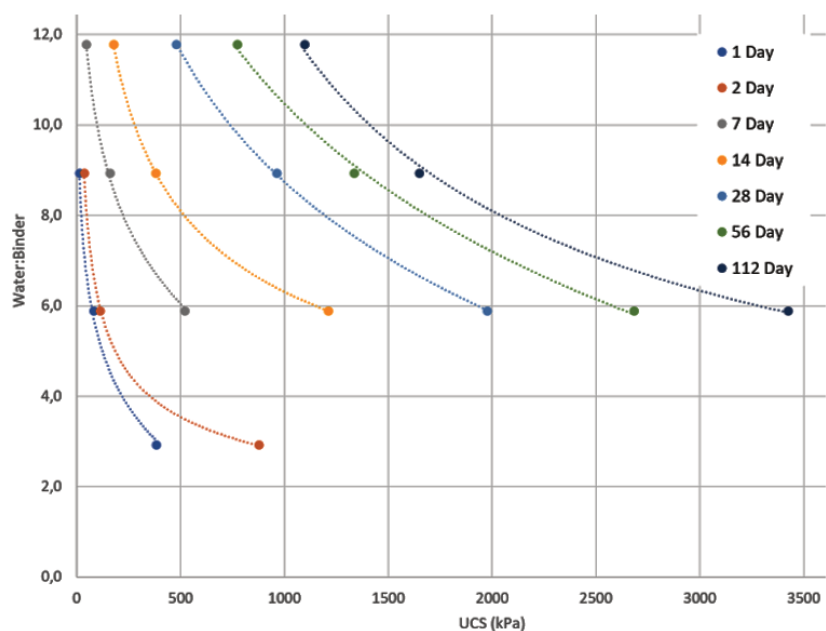

(a)

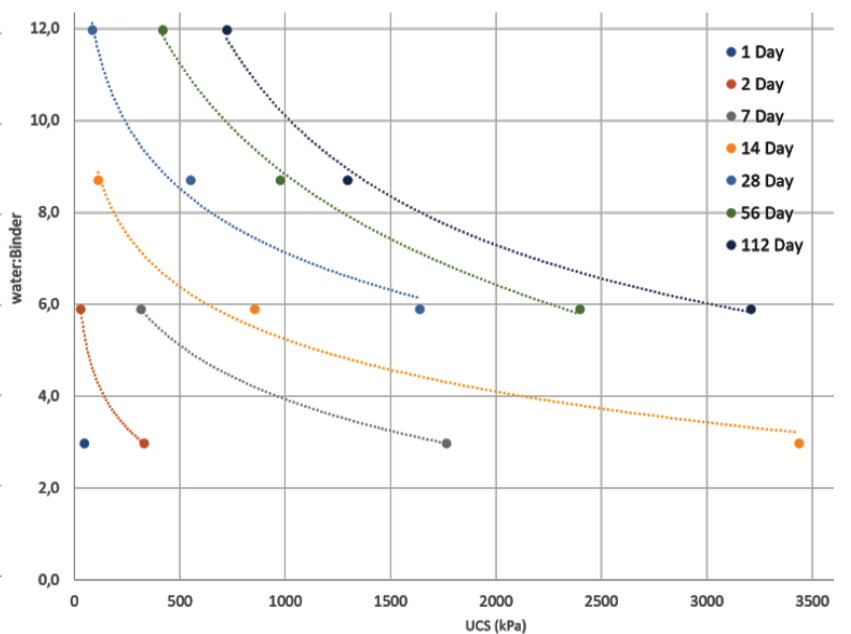

(b)

Figure 5 Water:binder ratio for (a) $0 \%$ sulphides and (b) $20 \%$ sulphides (Paterson \& Cooke Canada Inc. 2020, modified) 
These finer tailings forced an increase in the binder consumption by $4 \%$ to keep the same strength at the same curing age.

\subsection{Subjective decision making}

Prior to these changes, the recipes were chosen via charts comparing binder contents and strengths at specific curing ages. However, the data in these charts was outdated and not optimised. Their use was highly subjective and there was no provision made for the rationale behind the design decisions.

The new user-friendly template states all the inputs clearly which makes each design auditable. Additionally, the new template ensures that recipe selection is consistent.

\subsection{Change in stope dimensions and mining sequence}

The old required strength criteria for the adjacent stopes were based on the biggest stope dimensions with no consideration of the mining sequence beyond 56 days. A stope with its adjacent stope mined two years later would have the same recipe as a stope with its adjacent stope mined at 56 days of cure. This led to consuming more binder than often necessary. The new template allows the curing age to be adjusted according to the latest planning sequence up to just before pouring.

The new template also uses the actual dimensions of the stope to fill as opposed to the previously used maximum stope dimensions.

\subsection{Lower strength requirements}

The old approach advocated an extremely high binder content for the plugs above the sill pillars, instead of looking at the actual timing and strength required at the time of going underneath.

The backfill development was also authorised after 10 days of body curing with selected recipes, regardless of the strength reached in the plug or the body.

The new template looks at the required strength and timing to build the recipes, which is more cost effective.

Another benefit of the template is the ability to strategise on production gain through binder addition. A specific strength can be reached earlier with more binder or less sulphides. Less curing time can become a valuable option to increase the productivity, despite the additional costs that brings.

\subsection{Missing surface-underground link}

The old method did not link recipes with the backfill plant operations or take into account the percent solids of the paste nor the pump pressures.

Previously, the chosen high sulphides recipes would exceed the pump pressures, forcing the backfill plant operator to add extra water to the mix. This inevitably decreased the expected strength at the requested curing age, impacting the production unfavourably; blasting of adjacent stopes was delayed until the required paste strength was reached.

The new template includes the hydraulic analysis where each possible sulphides content is linked to its maximum percent solids. This ensures the selected recipes respect the maximum pump pressures.

The new template also translates the selected percent solids into a slump range so that operators can visualise the paste thickness. If the operator only reaches a slump of $190 \mathrm{~mm}$, while the selected slump for the requested $71 \%$ solids is between $170-185 \mathrm{~mm}$, they know to decease the water throughput to get back to the ideal slump. This would increase the pump pressure, but thanks to the hydraulic analysis, the requested percent solids will not make the pressure exceed its maximum limit. This is a great visual auto-correction tool for the operators. 


\section{$3 \quad$ Recipe template inputs}

The new recipe template had to incorporate all the Éléonore specific conditions mentioned above: stope environment and surroundings, planning and backfill sequences, hydraulic analysis, and specific stope dimensions. Figure 6 shows the inputs portion of the new template.

\begin{tabular}{|c|c|c|c|c|c|c|c|c|c|}
\hline$\Delta$ & A & B & $\mathrm{C}$ & $D$ & $\mathrm{E}$ & $\mathrm{F}$ & G & $\mathrm{H}$ & 1 \\
\hline 1 & \multirow{3}{*}{\multicolumn{9}{|c|}{ Paste Recipes }} \\
\hline 2 & & & & & & & & & \\
\hline 3 & & & & & & & & & \\
\hline 4 & Environment & & & & & & & & \\
\hline 5 & Water & no & & & & & & & \\
\hline 6 & Seismic Risk (liquefaction by vibrations) & no & & & & & & & \\
\hline 7 & Blast in proximity (dev or stope) under $14 \mathrm{~d}$ & yes & & & & & & & \\
\hline 8 & Time to blast in proximity & 14 & days & & & & & & \\
\hline 9 & Main drift in proximity & no & & & & & & & \\
\hline 10 & & & & & & & & & \\
\hline 11 & Sequence & & & & & & & & \\
\hline 12 & Exposed faced to the adjacent stopes & 1 & & & & & & & \\
\hline 13 & Above stope or Drive on cap & 28 & days & & & & & & \\
\hline 14 & Backfill dev (in drift BEFORE BROW) & 14 & days & & & & & & \\
\hline 15 & Backfill dev (in stope AFTER BROW) & NA & days & & & & & & \\
\hline 16 & Backfill dev below paste (future sill stope) & NA & days & & & & & & \\
\hline 17 & Adjacent stope (blast) & 28 & days & & & & & & \\
\hline 18 & & & & & & & & & \\
\hline 19 & Reticular Model & & & & & & & & \\
\hline 20 & Max sulphides \% & $20 \%$ & & $0 \%$ & $10 \%$ & $15 \%$ & $20 \%$ & $25 \%$ & \\
\hline 21 & $\%$ solids & $69,5 \%$ & & $71,0 \%$ & $70,5 \%$ & $70,0 \%$ & $69,5 \%$ & NA & $\%$ solids \\
\hline 22 & & & & 4300 & 4350 & 4425 & 4500 & NA & Pump Pressure \\
\hline 23 & Sulphides Tank and Planning & & & & & & & & \\
\hline 24 & $\%$ current sulphides tank level & $60 \%$ & & & & & & & \\
\hline 25 & $\begin{array}{l}\text { Coming stopes with low } \% \text { sulphides OR few voids to } \\
\text { fill? }\end{array}$ & no & & & & & & & \\
\hline 26 & & & & & & & & & \\
\hline 27 & Stope Dimensions & & & & & & & & \\
\hline 28 & Heigth & 29 & & & & & & & \\
\hline 29 & Length & 30 & & & & & & & \\
\hline 30 & Width & 7 & & & & & & & \\
\hline
\end{tabular}

\section{Figure 6 Recipe template inputs (template extract - translated)}

\subsection{Stope environment and surroundings}

Éléonore has to deal with water in open stopes, seismic-related events, neighbouring blasting activities, and stopes close to main access drives.

When an open stope fills with water while waiting to be backfilled, pumping and drainage holes are not always sufficient to empty it before CPB placement. This is why these 'water stopes' use specific high binder content recipes, overriding all the other conditions of the template. The high binder content can be explained as a compensation for the lower percent solids inside these stopes.

In the high seismic activity mining sectors, a higher factor of safety is applied to the required strength to force reaching a higher strength earlier.

When a neighbouring blast is planned within 14 days of the filling, the recipes are switched to reach a minimum strength limit before the blast. It is currently set at the $100 \mathrm{kPa}$ industry guideline. A blast is considered within the neighbourhood of the stope if it happens within $80 \mathrm{~m}$ for a production blast and within $20 \mathrm{~m}$ for a development blast. That $80 / 20 \mathrm{~m}$ rule is based on the Newmont Tanami mine strategy (Saros 2016). These distances are currently under revision to better represent the blasting impacts on the filling.

A last condition of higher strength at early age is applied to the recipe if the stope has no adjacent stopes but is near a high traffic drive. This ensures that if a traffic accident opens one of the paste walls, the paste will stay in place.

These restrictions are new to the recipe selection and have increased the annual binder consumption by about $15 \%$. Éléonore's management has accepted this increased cost due to the increase in overall mine safety. 


\subsection{Planning sequence}

The main information needed from mine planning is the mining sequence, providing the number of future paste faces exposed and the time between the end of the paste pour and the next activity.

A distinction is applied between the vertical and horizontal exposures. The four adjacent stopes on the same level bring one vertical exposure each. The underneath stope is the only horizontal exposure. Éléonore's current mining sequence is a pyramidal longitudinal sublevel retreat towards cross-cuts accesses, as shown in Figure 7. With the mineral zones being more than $15 \mathrm{~m}$ apart horizontally, stope 1 has up to two adjacent stopes, stope 3 and stope 6 , bringing up to two vertical exposures highlighted in purple. If the stope is on the first level of the bottom-up horizon (level $n$ ), it will also have one horizontal exposure as stope 10 for stope 1 , highlighted in red.

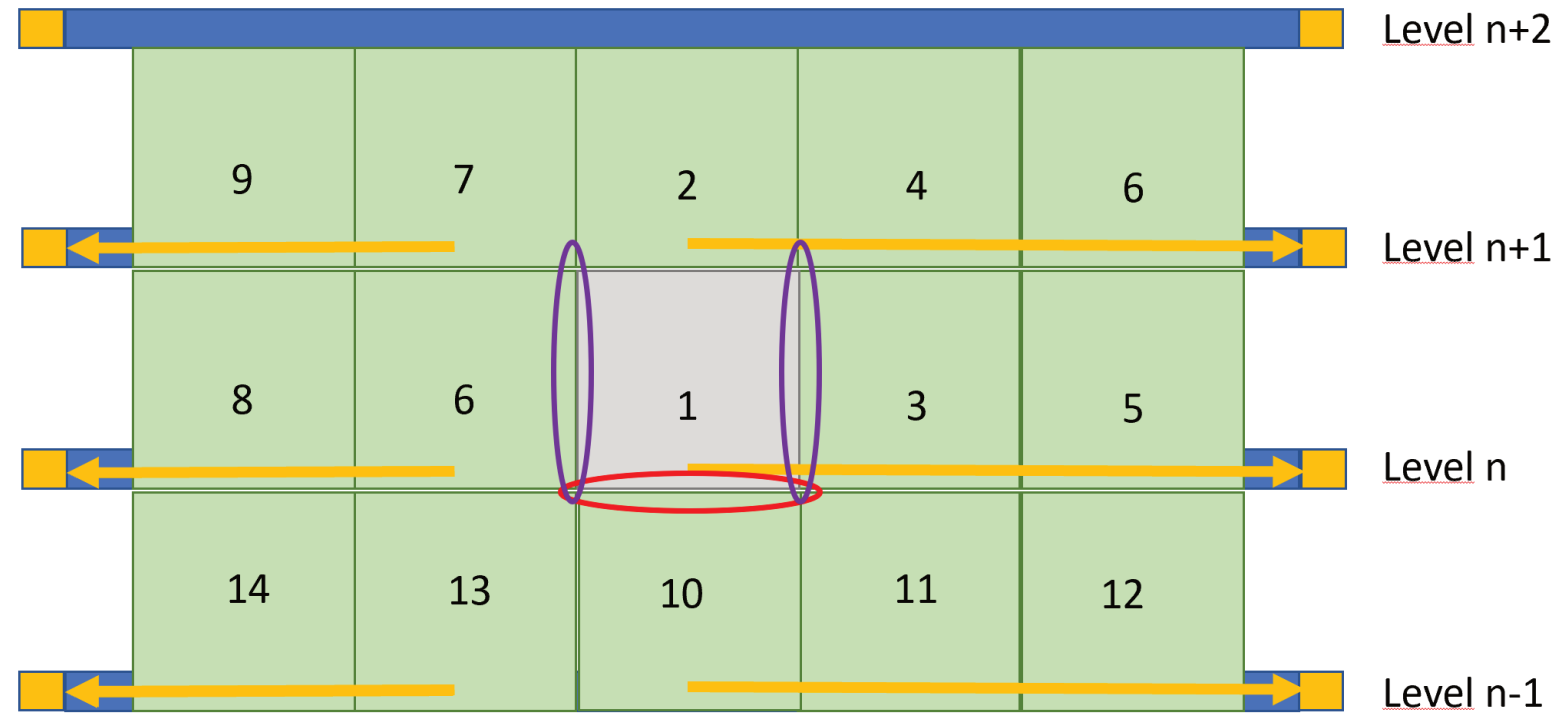

Figure 7 Éléonore typical mining sequence with highlighted exposures

Curing requirements are dictated by what activities are planned and when they will occur. Examples of these activities are:

- Driving on the cap or fill floor of the CPB stope.

- Backfill development in or under the paste.

- Mining of the adjacent stopes.

The longer the timing is, the lower the binder content needs to be to reach that required strength on time.

If there is no planned exposure, the minimum strength requirement is required to be reached after a 28 -day cure.

When exposures are involved, it is important to clarify the times between the activities. Different activities call for different strength. A strength meant to be reached at 28-day cure does not lead to the same recipe as a strength meant to be reached at 112 days. The binder content can actually be decreased by up to $50 \%$ depending on the required curing period.

The clarification of stope timing is determined by the planning team. Since 2021, they are required to fill the 'préparation d'une coulée de remblai' sheet or planning sheet that compiles all the times between the end of the pour and the next activities. Consequently, the short-term planning department decides on the times while the backfill team is responsible for respecting these times; the strength required has to be met within these periods. Figure 8 shows the time selection portion of the planning sheet. 


\begin{tabular}{|c|c|c|c|c|}
\hline \multicolumn{5}{|c|}{ 3. Mining Sequence } \\
\hline \multicolumn{5}{|c|}{$\begin{array}{l}\text { The timings correspond to the number of days between the end of the full filling of the stope and the next operation related steps around the } \\
\text { stope to fill. }\end{array}$} \\
\hline \multirow{2}{*}{\multicolumn{2}{|c|}{ 3.1 Time before driving over the cap: }} & $7 d$ & $14 d$ & $28 d$ \\
\hline & & $56 d$ & $112 \mathrm{~d}$ or + & NA \\
\hline \multirow{2}{*}{\multicolumn{2}{|c|}{ 3.2 Time before developping into paste (before brow): }} & $7 d$ & $14 d$ & $28 \mathrm{~d}$ \\
\hline & & $56 d$ & $112 \mathrm{~d}$ or + & NA \\
\hline \multirow{2}{*}{\multicolumn{2}{|c|}{ 3.3 Time before developping into paste (after brow): }} & $7 d$ & $14 d$ & $28 d$ \\
\hline & & $56 d$ & $112 \mathrm{~d}$ or + & NA \\
\hline \multirow{2}{*}{\multicolumn{2}{|c|}{ 3.4 Time before developping into paste (future sill stope): }} & $7 d$ & $14 d$ & $28 \mathrm{~d}$ \\
\hline & & $56 d$ & $112 \mathrm{~d}$ or + & NA \\
\hline \multirow{2}{*}{3.5} & 5 Time before the blast of the first adjacent stope (1st blast that & $7 d$ & $14 d$ & $28 d$ \\
\hline & exposes the paste): & $56 d$ & $112 \mathrm{~d}$ or + & NA \\
\hline
\end{tabular}

Figure 8 Extract of the backfill planning sheet - mining sequence (translated)

\subsection{Hydraulic analysis}

The hydraulic model is based on the tested rheology parameters as well as the surface and underground paste reticulation system, the pipe characteristics, the paste throughput and the amount of sulphides. The black line on Figure 9 shows a typical pipeline trace for a stope poured from level 830. Once calibrated, the model identifies the percent solids required for the different sulphide contents while still respecting the maximum pump pressure. The hydraulic model in Figure 9 is for a CPB with no sulphide at $71 \%$ solids.

Total Pipeline Length $(\mathrm{m})$

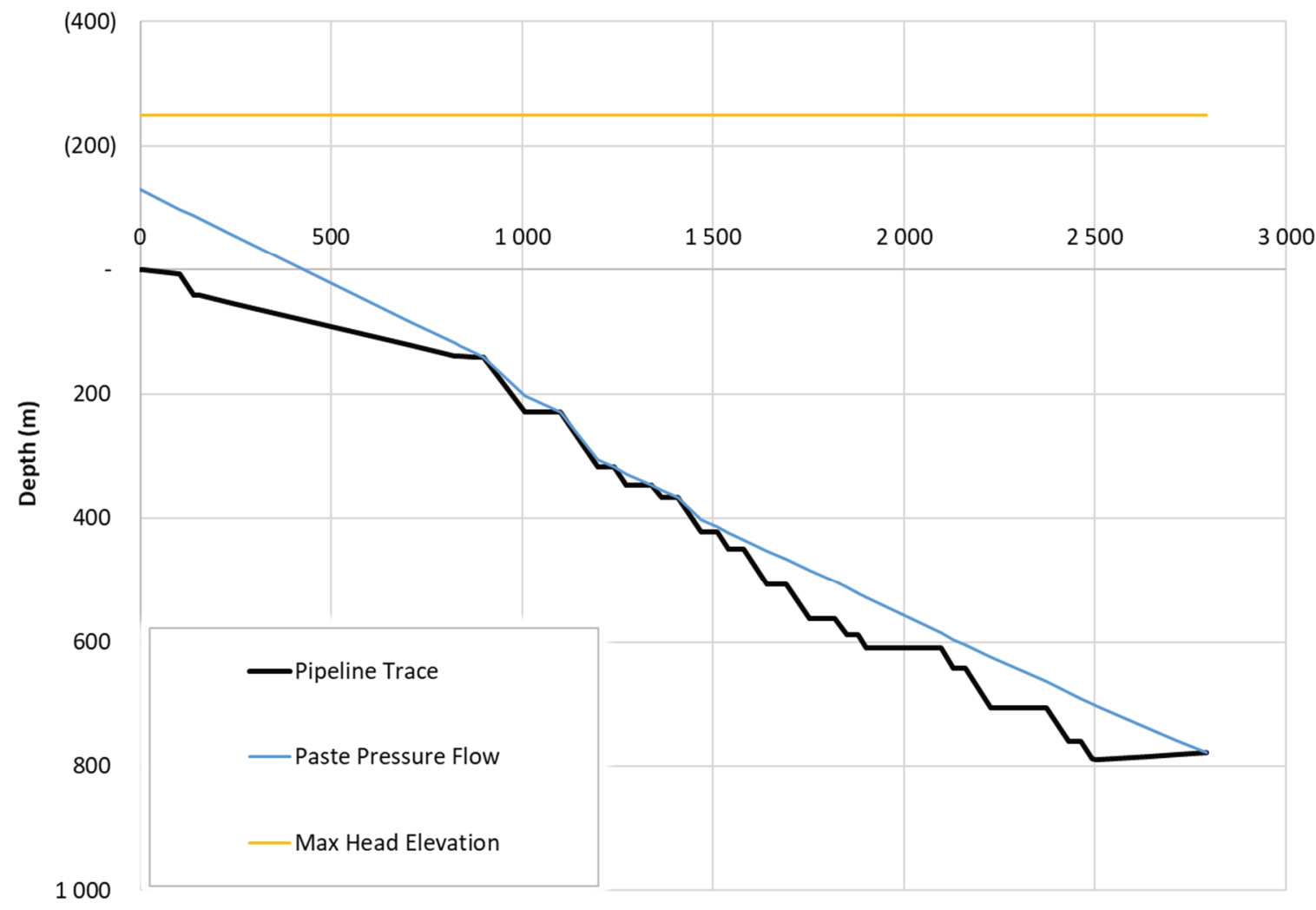

Figure 9 Reticulation model for a stope poured from level 830 ( $0 \%$ sulphides and $71 \%$ solids) 
Figure 10 shows the reticulation model for the same stope as Figure 9 with:

- $25 \%$ sulphides at $71 \%$ solids in green.

- $25 \%$ sulphides at $70 \%$ solids in grey.

- $15 \%$ sulphides at $71 \%$ solids in orange.

Total Pipeline Length (m)

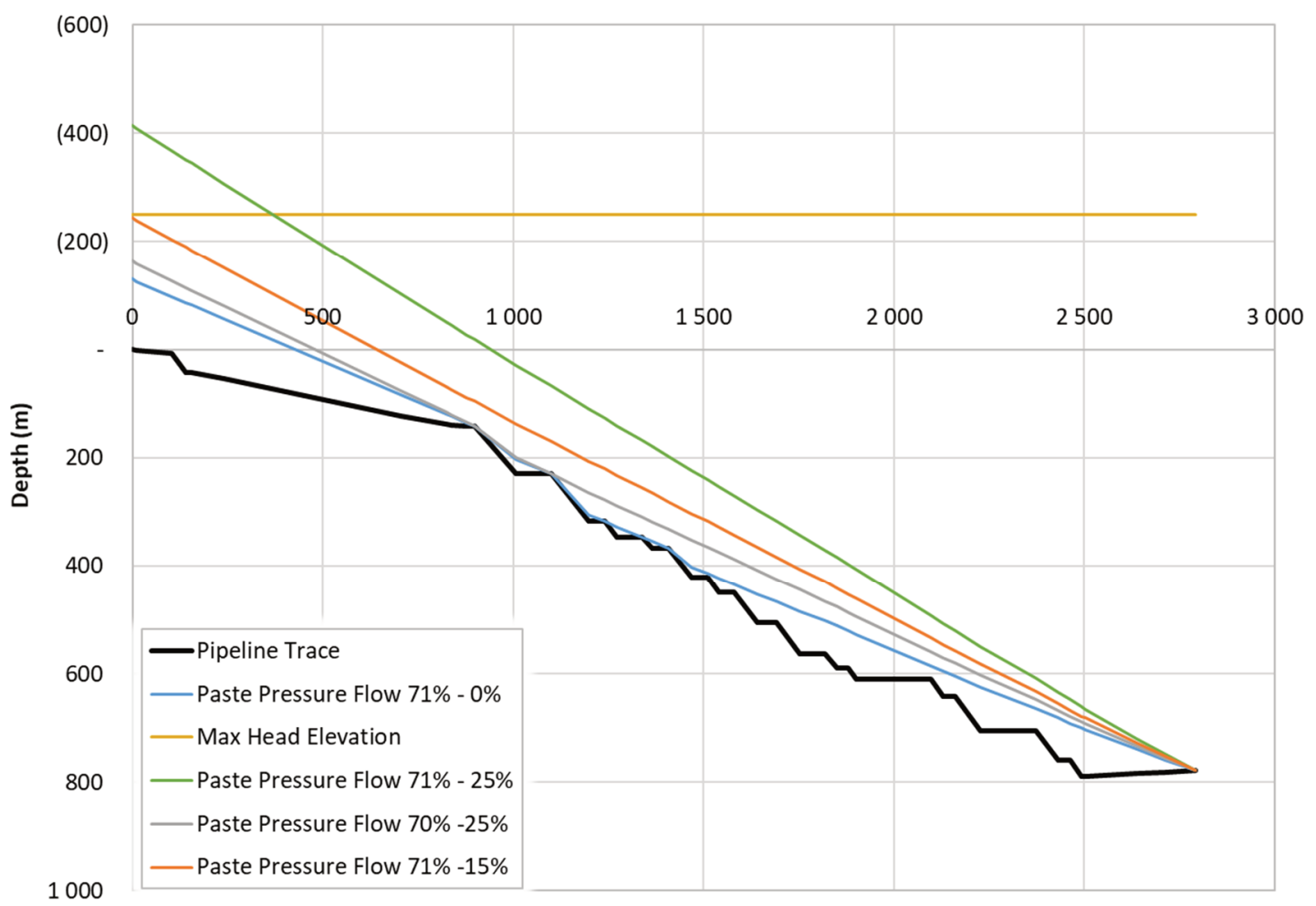

Figure 10 Reticular model for the same stope as Figure 9 ( $25 \%$ sulphides and $71 \%$ solids)

In Figures 9 and 10, the maximum pump pressure limit is marked by the yellow horizontal line at 4,500 $\mathrm{kPa}$ (or $\sim 250 \mathrm{~m}$ of CPB pressure head). This demonstrates that a $25 \%$ sulphide mix cannot work with $71 \%$ solids for that particular stope, without bringing the pump pressure above its maximum. To stay within the pressure limits while keeping a sulphides content of $25 \%$, the percent solids of that mix needs to be around $70 \%$ solids. To keep the percent solids at $71 \%$, the sulphides content needs to be decreased to $15 \%$.

To ensure all the sulphides tailings are sent back underground, the recipes selected maximise the sulphide content. As demonstrated above, higher sulphide content generally means increased yield stress and viscosity, which, in turn, leads to increased pump pressure requirements.

Some reticulation configurations do not allow transportation of the maximum sulphide CPBs. These mixes either exceed the pump pressures or require excessive binder contents to compensate for the lower percent solids. As such, the Éléonore percent solids varies between 69 and $71 \%$ while the sulphide content varies between 0 and $25 \%$.

A higher solids content than $71 \%$ is currently not achievable, due to lack of confidence in the age of the surface pipeline. The pump pressure limits are under investigation and are capped at 4,500 kPa currently. A solids content lower than $69 \%$ introduces slack flow-related issues and increases binder consumption rates higher than what the plant can provide. Due to this limit, the sulphide content requires adjustment. Until further investigation on this topic, the percent sulphides is capped at $25 \%$ to keep the percent solids manageable.

The hydraulic analysis enables generating optimised recipes that meet both the pump criteria and the required strength. 


\subsection{Backfill sequence}

The mill is required to stop operating when the sulphide tank reaches $85 \%$ of its capacity. To avoid that situation, the template forces the use of a $25 \%$ sulphide mix when the sulphide tank reaches $65 \%$ capacity. However, the sulphide tank cannot be completely emptied to avoid segregation issues in the tank. Due to this, when the tank level decreases below $30 \%$, the template uses the minimum sulphide content possible.

The template also looks at the future void requirements to ensure a balanced sulphide addition. If the expected future sulphide usage is low (i.e. water inflows, to accommodate an already high binder content, etc.), the current void will be filled with the maximum sulphide content possible.

The template highlights the stopes that can accommodate higher sulphide content without large binder content increases. While scheduling with the sulphide tank level in mind, the backfill technicians are able to choose the stopes that can have maximum sulphide contents, without incurring extra binder costs.

\subsection{Stope dimensions}

In the past, the strength stability estimation method used the largest possible stope dimensions. This assumption was valid initially as the original Éléonore stopes were larger than current stopes. However, the stopes are now generally mined longitudinally and can have substantially different exposure geometries. These varying geometries have an impact on the required stability strength requirements (i.e. the narrower the stope, the stronger the arching effect, the lower the required strengths). Éléonore currently uses cavity monitoring surveys (CMS) of the empty stope to determine the actual exposure dimension for analysis. This has decreased the strength requirements by up to $68 \%$, which has decreased Éléonore's binder usage by $18 \%$.

\subsection{Inputs summary}

Table 1 compares the inputs between the old and new methods.

\section{Table 1 Old and new method inputs comparison}

\begin{tabular}{lll}
\hline Stope environment and surroundings & Old method & New method \\
\hline Water in open stopes & Manual & Automatic \\
Seismic-related events & Not included & Included \\
Neighbouring blasting activities & Not included & Included \\
Stopes close to main access drives & Not included & Included \\
Planning sequence & Constant & Customised \\
Hydraulic analysis & None & Customised \\
Backfill sequence & Manual & Semi-automated (flagged when over limits) \\
Stope dimensions & Largest & Customised per CMS data \\
\hline
\end{tabular}

\section{$4 \quad$ Recipe template}

The recipe template provides Éléonore with an auditable and objective paste recipe selection method.

The template starts by clearly stating the inputs, as explained above. It then calculates the strength requirements to end with the selection of the final recipes set that is adjustable until pouring begins. 


\subsection{Required UCS}

The stability strength estimation method utilised by Éléonore was the Mitchell Method (Mitchell et al. 1982). However, as Éléonore's mining method now requires multiple exposures, as well as a desire to decrease backfill strength with height, it changed to a method based on Terzaghi's soil arching theory (Baldwin \& Grice 2000).

The CPB strength is calculated based on:

- The dimensions of the stope.

- The arching effect.

However, this initial strength can be adjusted based on any mining situations or other strength requirements. These include:

- The backfill development in the paste.

- The backfill development under the paste.

- The sill development.

- A higher strength cap if the CPB mass needs to be driven on.

\subsection{Recipes sets}

A pour design breaks the stope into three sections as defined below:

- One recipe for the plug of a usual $8 \mathrm{~m}$ high.

- One recipe for the body.

- One recipe for the cap or fill floor representing the last $3 \mathrm{~m}$ of paste.

In the past, only one condition was looked at; usually determined arbitrarily as to the most constraining. The recipe sets configuration of the template reports a set of recipes for every possible stope condition. It then combines them into one ideal final recipe set. In that sense, the final recipe set can select the final plug recipe from a different condition set than the body or cap recipes.

Éléonore's template looks at six recipe sets equivalent to the six conditions explained above, before automatically selecting the final one.

\subsection{Final recipes selection}

The final set is selected based on the most restrictive condition for every portion of the stope (i.e. the condition requesting the most binder content at the default amount of sulphides or requiring the highest strength the earliest).

That binder content is then adjusted according to the sulphides content required at the time of filling and the estimated strength and curing age, based on the percent solids and water:binder ratio. This means that all the final recipes per portion of stope are expected to reach the same strength at the same specified curing age, even though they contain different sulphides contents.

If any of the above conditions change, the template is flexible enough so that it can be modified with any changes in the real-time conditions prior to pouring commencing. 
Figure 11 shows the final recipes set of the template.

\begin{tabular}{|c|c|c|c|c|c|c|c|c|}
\hline 1 & A & B & C & D & $E$ & $\mathrm{~F}$ & G & $\mathrm{H}$ \\
\hline 95 & FINAL Recipes with different \% sulphides & $\begin{array}{l}\text { Asked \% } \\
\text { sulphides }\end{array}$ & $\begin{array}{l}\text { Modified \% } \\
\text { solids for } \\
\text { Asked \% } \\
\text { sulphides }\end{array}$ & Strength & Time & $\%$ sulphides & w.b ratio & $\%$ binder \\
\hline 96 & Plug & $15 \%$ & $70,0 \%$ & 195 & 14 & $15 \%$ & 9,6 & $5,1 \%$ \\
\hline 97 & Body & $15 \%$ & $70,0 \%$ & 130 & 14 & $15 \%$ & 10,4 & $4,7 \%$ \\
\hline 98 & Cap & $15 \%$ & $70,0 \%$ & 130 & 14 & $15 \%$ & 10,4 & $4,7 \%$ \\
\hline
\end{tabular}

Figure 11 Final recipes selection (template extract - translated)

\section{$5 \quad$ Costs analysis}

The recipe template was created to both facilitate consistent recipes selection and implement safer filling practices. With these, the template also brought some costs savings and production opportunities.

\subsection{Costs savings}

Since Éléonore's CPB is extremely cost-sensitive to binder, by decreasing its consumption through the template, Éléonore benefited from significant costs savings.

The template managed to compensate for the inevitable binder consumption increase brought by the additional safety measures (blast, seismicity and adjacency to main access drive) and change in tailings particle sizes. These generated an increase of $25 \%$ in binder consumption or about CAD 2.83M per year. However, the new strength requirements method, actual stope dimensions and mining sequence consideration dropped the overall binder consumption by $21 \%$ or about CAD $2.78 \mathrm{M}$ per year. This means that the improvements to Éléonore's filling practices have not cost the operation any additional funds, and this was acceptable to management given the improved designs and safety implications.

Moreover, the template can adjust the sulphide content to optimise the binder consumption with the mining sequence. Even though the mill has never shut down due to reaching the maximum sulphide tank level, the last-minute changes in sulphide content to avoid such a shutdown have had a negative impact on the binder consumption. As the template highlights which stopes can accommodate higher sulphide contents, without greatly increasing the binder content, the technician is able to select the most suitable stopes over a two-week backfill plan. If an additional $1 \%$ binder is avoided for one stope a month due to this improved sulphide management process, the savings could represent CAD $0.25 \mathrm{M}$ per year.

\subsection{Production opportunities}

The automated template simplifies the comparison of different filling scenarios, such as reducing the curing time before developing in paste or better adjusting the recipes to fit the pump limits. These options could drive potential production increases over the year.

As an example, if the selected recipe brings down the wait time between the filling and backfill development from 14 to seven days for one stope every two months, the annual production could be increased by 42 days. Depending on the selected stopes, the additional binder costs implied by that change is usually largely overtaken by the value of earlier production.

Similarly, a change in recipes without percent solids adjustments can lead to production losses. The time to reach the required strength and hence to blast the adjacent stope or returning into the paste for CPB development is increased by at least a couple of days. The unplanned drop in percent solids is responsible for that delay. With the hydraulic analysis, the template can avoid such a delay. If this is prevented for an average of one stope every two months, the annual production could be increased by 12 days. 


\section{$6 \quad$ Future improvements}

Paste samples are tested daily at the onsite lab for production purposes and to augment the CPB database. The objective is to keep adding different curing times to the database to periodically adjust the recipes to better match the required strength and curing time.

Along with the extended database, the water:binder ratio will also be reviewed. These curves are the basis for adapting the binder content while switching between the different sulphide contents. The more accurate they are, the better the recipes will meet the strength expectations.

The 80/20 m blast exclusion zone guideline from Tanami (Saros 2016) will be updated by the end of 2021 according to the actual Éléonore blast loads, so this condition can become less restrictive while still maintaining safety requirements.

Based on onsite experience, the Éléonore early age stability strength is expected to be lower than $100 \mathrm{kPa}$. For that reason, a laboratory testing campaign targeting early curing ages with seismic events is also on the list of improvements.

Some tests are currently underway with operations regarding the cap strength requirements. It is believed that the current $150 \mathrm{kPa}$ required at the time of driving on the cap could be reduced. The other option is to consider the strength required when tipping the waste rock over the paste cap.

Since the default recipes for the stopes with water are costly due to the high binder content, optimisation of these recipes is key to reduce the binder consumption. The water may not influence the in situ heavier paste as much as believed. It is possible that the binder content could be drastically reduced without impacting the expected final strength.

\section{Conclusion}

The recipe template makes the recipe selection process more comprehensible and consistent. It also brings along safer filling practices, optimised binder contents with cost reduction and flexibility to the production schedule.

With no increases in binder costs and improved options to speed up the mining cycles, the new paste recipe selection method has proven its worth.

\section{References}

Baldwin, G \& Grice, AG 2000, 'Engineering the new Olympic Dam backfill system', Proceedings of MassMin 2000, The Australasian Institute of Mining and Metallurgy, Melbourne, pp. 721-734.

Guido, S, Grenon, M \& Germain, P 2017, 'Stope performance assessment at the Goldcorp Eleonore mine using bivariate analysis', Proceedings of the ISRM 2017 International Symposium: Rock Mechanics for Africa AfriRock, The Southern African Institute of Mining and Metallurgy, Johannesburg.

Mitchell, RJ, Olsen, RS \& Smith, JD 1982, 'Model studies on cemented tailings used in mine backfill', Canadian Geotechnical Journal, vol. 19, pp. 14-28.

Paterson \& Cooke Canada Inc. 2020, Eleonore Paste Capacity Review - Test Work Report, external report for Newmont Goldcorp Eleonore gold mine.

Saros 2016, NTO01 - Assessment of Blasting Impacts on Active Paste Filled Stopes, external report for Newmont Tanami Operations, Saros, Brisbane. 
